\title{
MÉTODOS DE EXTRAÇÃo PARA QUANTIFICAÇÃo DE MANGANÊS DISPONÍVEL EM FERTILIZANTES
}

\author{
Ana Rosa Ribeiro Bastos*, Janice Guedes de Carvalho, Eric Victor de Oliveira Ferreira e \\ Leilson Antônio de Faria Júnior \\ Departamento de Ciência do Solo, Universidade Federal de Lavras, CP 3037, 37200-000 Lavras - MG, Brasil \\ José Carlos Alcarde \\ Departamento de Ciências Exatas, Escola Superior de Agricultura "Luiz de Queiroz", Universidade de São Paulo, CP 9, \\ 13418-900 Piracicaba - SP, Brasil
}

Recebido em 16/8/06; aceito em 30/3/07; publicado na web em 6/8/07

\begin{abstract}
EXTRACTION METHODS FOR QUANTIFICATION OF AVAILABLE MANGANESE IN FERTILIZERS. The solubility of Mn in different fertilizers $\left(\mathrm{MnSO}_{4} \cdot \mathrm{H}_{2} \mathrm{O}\right.$-p.a., $\mathrm{MnO}_{2}$-p.a.+MnO-Ind., $\mathrm{MnO}_{2}$-Ind.+MnO-Ind., $\mathrm{MnO}_{2}$-p.a., $\mathrm{MnO}_{2}$-Ind. and $\mathrm{MnO}$-Ind.) was determined using different methodologies: total content and soluble contents in water, $10 \% \mathrm{H}_{2} \mathrm{SO}_{4}$, citric acid at $20 \mathrm{~g} \mathrm{~L}^{-1}$, diluted neutral ammonium citrate, $(1+9)$ and DTPA at $0.005 \mathrm{~mol} \mathrm{~L}^{-1}$. The Mn solubilities in the latter three extractors were assessed after agitation of the sample for one hour and after boiling for 5 minutes. The extraction procedure using neutral ammonium citrate $(1+9)$, at 1:100, with agitation for one hour, was shown to be the most adequate to assess the availability of Mn in fertilizers.
\end{abstract}

Keywords: manganese; sources; availability.

\section{INTRODUÇÃO}

O manganês é um elemento essencial para o crescimento e o desenvolvimento das plantas. Apresenta efeitos expressivos na nutrição das plantas, tanto do ponto de vista de deficiência como de toxicidade, com perdas significativas na produção de plantas cultivadas sob ambos os efeitos ${ }^{1}$.

A eficiência agronômica do fertilizante contendo manganês depende das características intrínsecas do adubo. Além disso, a ocorrência de deficiência desse elemento em plantas cultivadas em solos aos quais foram adicionados fertilizantes contendo esse micronutriente sugere que nem todo o manganês contido nos fertilizantes está disponível às plantas ${ }^{1}$. Desse modo, o extrator comumente utilizado na quantificação do $\mathrm{Mn}$ não possui a capacidade de discriminar a quantidade de manganês realmente disponível.

A determinação do manganês "disponível" em fertilizantes não é feita pelos laboratórios no Brasil, uma vez que a legislação brasileira vigente, que define e regulamenta as fontes de micronutrientes, faz referência apenas, em termos de garantia, ao teor total, sem nenhuma exigência quanto à solubilidade, eficiência de absorção, ao transporte na planta e à sua eficiência agronômica. A falta de métodos adequados para quantificar o Mn disponível vem dificultando, para pesquisadores e agricultores, a avaliação de fontes confiáveis para o fornecimento desse nutriente às plantas ${ }^{2}$. A legislação atual pode ser considerada deficiente quando estabelece a determinação apenas dos teores totais de micronutrientes em fertilizantes ${ }^{3}$. Nessa determinação, o ataque enérgico com ácidos minerais fortes e calor possibilita a solubilização de fontes que dificilmente teriam alguma solubilização mais efetiva no solo. A disponibilidade de micronutrientes em fertilizantes comerciais foi verificada determinando-se a solubilidade dos mesmos em extratores químicos e correlacionado-os com a absorção por plantas de arroz. Com exceção do boro, a garantia pelo teor total não indicou a real disponibilidade dos micronutrientes contidos nos fertilizantes. Os extratores que se mostraram mais promissores fo-

*e-mail: arosa@ufla.br ram o ácido cítrico $20 \mathrm{~g} \mathrm{~L}^{-1}$, citrato neutro de amônio (1+9) e DTPA $0,005 \mathrm{~mol} \mathrm{~L}^{-12}$. Mais recentemente, foi confirmada a não validade da garantia dos fertilizantes contendo zinco pelo teor total, sugerindo que o extrator citrato neutro de amônio $(1+9)$, na relação 1:100 e com fervura por $5 \mathrm{~min}$, seria o extrator mais adequado para avaliação da disponibilidade de $\mathrm{Zn}$ nos fertilizantes ${ }^{4}$.

O presente trabalho visou quantificar o manganês disponível em fertilizantes, por meio de soluções extratoras, e correlacioná-lo com a absorção desse elemento pelas plantas de arroz, em dois cultivos sucessivos, em casa de vegetação. Procurou-se identificar o efeito imediato e o possível efeito residual do nutriente e, com isso, eleger o extrator ou os extratores mais promissores para definir a disponibilidade de Mn presente nos fertilizantes.

\section{PARTE EXPERIMENTAL}

O estudo foi conduzido no Departamento de Ciência do Solo, da Universidade Federal de Lavras (UFLA), constituindo-se na determinação dos teores totais e solúveis de Mn de seis fertilizantes e avaliação de sua correlação com a absorção desse micronutriente por plantas de arroz (Oryza sativa L.). Foram utilizados fertilizantes cedidos pela indústria de fertilizantes NUTRIPLANT e produtos de origem p.a. para comparação, todos na forma de pó. Esses produtos foram: sulfato de manganês monoidratado p.a. $(32,5 \%$ $\mathrm{Mn})-\mathrm{MnSO}_{4} \cdot \mathrm{H}_{2} \mathrm{O}, \mathrm{F} 1$, bióxido de Mn p.a. + monóxido de Mn Industrial $(62 \% \mathrm{Mn})-\mathrm{MnO}_{2}$ p.a. + $\mathrm{MnO}$ Ind., F2, bióxido de $\mathrm{Mn}$ Industrial + monóxido de $\mathrm{Mn}$ Industrial $(55 \% \mathrm{Mn})-\mathrm{MnO}_{2}$ Ind. + $\mathrm{MnO}$ Ind., F3, bióxido de $\mathrm{Mn}$ p.a. (63\% Mn)- $\mathrm{MnO}_{2}$ p.a., F4, bióxido de $\mathrm{Mn}$ Industrial (50\% Mn)- $\mathrm{MnO}_{2}$ Ind., F5, monóxido de Mn Industrial (60\% Mn)- MnO Ind., F6.

Para análise do teor total (TT) de Mn foram utilizados dois extratores, $\mathrm{HCl}$ e $\mathrm{HCl}+\mathrm{HNO}_{3}$ (água-régia), conforme os procedimentos descritos pelo Ministério da Agricultura $^{5}$. Os teores de $\mathrm{Mn}$ solúveis em água e nas soluções de ácido cítrico (AC $20 \mathrm{~g} \mathrm{~L}^{-1}$, $1: 100)$, citrato neutro de amônio (CNA 1+9, 1:100) e de ácido dietilenotriaminopentacético (DTPA $0,005 \mathrm{~mol} \mathrm{~L}^{-1}, 1: 100$ ) foram determinados segundo o método de Vale e Alcarde ${ }^{2,4}$. Os teores de 
Mn solúvel em $\mathrm{H}_{2} \mathrm{SO}_{4} 10 \%$ foram também determinados de acordo com o Ministério da Agricultura 5 . Efetuaram-se três repetições para cada método de análise utilizado.

As amostras dos produtos foram moídas manualmente em gral de porcelana e passadas em peneira de $\left.0,84 \mathrm{~mm}_{(\mathrm{ABNT}} \mathrm{n}^{\circ} 20\right)$.

\section{Extrações}

\section{Teor total de manganês}

Foi utilizado o procedimento para fertilizantes minerais do tipo não fritas, utilizando-se somente $\mathrm{o} \mathrm{HCl}^{5,6}$.

Realizou-se também a extração com o teor total em água régia $\left(\mathrm{HCl}+\mathrm{HNO}_{3}\right)$ conforme os procedimentos descritos pelo Ministério da Agricultura 5 .

\section{Teor de manganês solúvel em água}

O procedimento foi o mesmo realizado por Vale e Alcarde A $^{2,4}$ quando utilizaram o elemento zinco.

Teores de manganês solúvel nas soluções de AC $20 \mathrm{~g} \mathrm{~L}^{-1}$ (1:100), CNA (1+9) (1:100) е DTPA 0,005 mol $L^{-1}(1: 100)$

Os métodos de extração, por agitação ou por fervura, foram os mesmos para todos os extratores. Para estas extrações a metodologia utilizada foi a mesma, somente modificando-se o extrator ${ }^{2,4}$.

A solução de DTPA foi a mesma utilizada atualmente para a extração de micronutrientes metálicos disponíveis em solos, pelo princípio da quelação ${ }^{7}$. Uma mudança da relação foi proposta entre a massa da amostra com o extrator quando se utilizou fertilizantes $^{2}$. Para solo a relação utilizada é de 1:2, enquanto para fertilizante, por ter uma concentração bem maior de micronutrientes, os autores propuseram a relação 1:100.

\section{Extração por agitação}

Após a transferência de $1,000 \mathrm{~g}$ da amostra para erlenmeyer de $250 \mathrm{~mL}$, foram adicionados $100 \mathrm{~mL}$ da solução extratora. A mistura, tampada com rolha de borracha, foi colocada em agitador tipo Wagner e agitada por $1 \mathrm{~h}$, a 30-40 rpm. Em seguida, foi filtrada em papel faixa branca, recebendo o filtrado em balão de $250 \mathrm{~mL}$. Lavou-se o erlenmeyer e o filtro com porções de água destilada e completou-se o volume. Foi preparada uma prova em branco.

\section{Extração por fervura}

Após a transferência de $1,000 \mathrm{~g}$ da amostra para erlenmeyer de $250 \mathrm{~mL}$, foram adicionados $100 \mathrm{~mL}$ da solução extratora, cobriuse a mistura com vidro de relógio e procedeu-se à fervura por 5 min, em chapa aquecedora. Em seguida, filtrou-se em papel faixa branca, recebendo o filtrado em balão de $250 \mathrm{~mL}$. Lavou-se o erlenmeyer e o filtro com porções de água destilada e completouse o volume. Foi preparada uma prova em branco.

\section{Teor de manganês solúvel em $\mathrm{H}_{2} \mathrm{SO}_{4} 10 \%(\mathrm{v} / \mathrm{v})$}

Após a transferência de $0,500 \mathrm{~g}$ da amostra para erlenmeyer de $250 \mathrm{~mL}$, foram adicionados $30 \mathrm{~mL}$ da solução $\mathrm{H}_{2} \mathrm{SO}_{4} 10 \%$ (v/v), fervendo-se por $45 \mathrm{~min}$ em chapa aquecedora. Em seguida, retirou-se da chapa e deixou-se esfriar. Filtrou-se em papel faixa branca, recebendo o filtrado em balão de $500 \mathrm{~mL}$. Lavou-se o erlenmeyer e o filtro com porções de água destilada e completou-se o volume. Foi preparada uma prova em branco.

Os teores de Mn foram quantificados por espectrofotometria de absorção atômica. Utilizou-se um espectrômetro de absorção atômica de chama, Carl Zeiss Jena AAS4, com chama de gás acetileno e lâmpada de cátodo oco. Os dados de solubilidade de Mn foram submetidos à análise estatística pelo Sistema de Análise de Variância, SISVAR, UFLA ${ }^{8}$, e comparados pelo teste de Scott e Knott, a $5 \%$ de probabilidade 9 .

Efetuou-se, também, a identificação dos principais minerais presentes e eventuais resíduos nas amostras dos fertilizantes, por análise em difratômetro de raios-X, dotado de goniômetro vertical e geometria $\theta$, variação angular de $2-60^{\circ} 2 \theta$, radiação de $\operatorname{CoK} \alpha$, filtro de Fe e velocidade de exposição de $1^{\circ} 2 \theta$.

\section{Avaliação do aproveitamento de manganês por plantas de arroz}

A disponibilidade de Mn dos fertilizantes para a cultura do arroz foi estudada em experimento de casa de vegetação, em um solo com baixo teor de Mn. O solo, classificado como Neossolo Quartzarênico Órtico ${ }^{10}$, apresentava as seguintes características químicas e físicas: $\mathrm{pH}$ em água $(1: 2,5)$

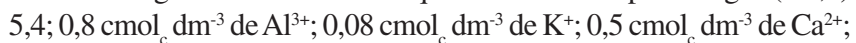

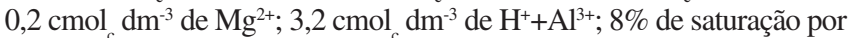
bases (V); $13 \mathrm{~g} \mathrm{dm}^{-3}$ de MO; 6,6 mg dm${ }^{-3}$ de P; 7,0 $\mathrm{mg} \mathrm{dm}^{-3}$ de Mn (Mehlich 1); 1,6 mg dm${ }^{-3}$ de Mn (DTPA); $52 \mathrm{~g} \mathrm{dm}^{-3}$ de argila; $23 \mathrm{~g} \mathrm{dm}^{-3}$ de silte e $925 \mathrm{~g} \mathrm{dm}^{-3}$ de areia. Essas análises do solo foram efetuadas segundo a metodologia da EMBRAPA ${ }^{11}$ e o teor de Mn (DTPA), de acordo com Lindsay e Norvell ${ }^{7}$.

Foram programados quatro tratamentos nas doses de $0 ; 5 ; 10 \mathrm{e}$ $20 \mathrm{mg} \mathrm{dm}^{-3}$ de Mn de cada fonte, compondo um fatorial 4x6 (4 doses e 6 fontes). Utilizou-se o delineamento experimental inteiramente casualizado com quatro repetições, totalizando 96 parcelas em vasos de $5 \mathrm{mg} \mathrm{dm}^{-3}$ de solo.

Antes do plantio, aplicou-se carbonato de cálcio p.a. e hidroxicarbonato de magnésio p.a. na relação Ca: $\mathrm{Mg} \mathrm{3:1,} \mathrm{para} \mathrm{ele-}$ var a saturação por bases a $50 \%^{12}$. Os vasos permaneceram incubados por 15 dias, com umidade em torno de $60 \%$ do volume total de poros (VTP). A seguir, foram adicionados, em $\mathrm{mg} \mathrm{dm}^{-3}$ de solo, macronutrientes (N: 300, P: 200, K: 240, Ca: 90, Mg: 30 e S: 50) e micronutrientes (B: 0,5; Cu: 1,5; Zn: 5; Mo: 0,1 e Fe: 5), na forma de reagentes p.a. ${ }^{13}$. Os nutrientes foram aplicados em solução e misturados uniformemente ao solo. O nitrogênio e o potássio foram parcelados em 3 aplicações iguais: no plantio, aos 35 e 55 dias após a emergência das plântulas. As fontes utilizadas foram: $\mathrm{NH}_{4} \mathrm{NO}_{3},\left(\mathrm{NH}_{2}\right)_{2} \mathrm{CO},\left(\mathrm{NH}_{4}\right)_{2} \mathrm{SO}_{4}, \mathrm{NH}_{4} \mathrm{H}_{2} \mathrm{PO}_{4}, \mathrm{Ca}\left(\mathrm{H}_{2} \mathrm{PO}_{4}\right)_{2} . \mathrm{H}_{2} \mathrm{O}$, $\mathrm{KNO}_{3}, \mathrm{KCl}, \mathrm{Ca}\left(\mathrm{NO}_{3}\right)_{2} \cdot 4 \mathrm{H}_{2} \mathrm{O}, \mathrm{MgSO}_{4} \cdot 7 \mathrm{H}_{2} \mathrm{O}, \mathrm{H}_{3} \mathrm{BO}_{3}, \mathrm{CuSO}_{4} .5 \mathrm{H}_{2} \mathrm{O}$, $\mathrm{ZnSO}_{4} \cdot 7 \mathrm{H}_{2} \mathrm{O},\left(\mathrm{NH}_{4}\right)_{6} \mathrm{Mo}_{7} \mathrm{O}_{24} \cdot 4 \mathrm{H}_{2} \mathrm{O}, \mathrm{FeSO}_{4} \cdot 7 \mathrm{H}_{2} \mathrm{O}$.

Todos os produtos contendo $\mathrm{Mn}$ foram adicionados antes do plantio, na forma de pó, sendo misturados em todo o solo contido no vaso, exceto o sulfato de Mn que foi aplicado em solução. As sementes de arroz, cultivar Canastra, foram tratadas com solução de hipoclorito de sódio a $1 \%(\mathrm{v} / \mathrm{v})$, colocando-se dez sementes por vaso. Após a germinação foram desbastadas para 6 plantas uniformes e vigorosas por vaso.

Aos 60 dias da germinação, no perfilhamento, foram cortadas quatro plantas por vaso rente ao solo para avaliação de matéria seca e análise foliar. A parte aérea foi lavada em água destilada e deionizada, secada até peso constante em estufa de circulação forçada de ar a $60{ }^{\circ} \mathrm{C}$, pesada e moída em moinho tipo Wiley. Efetuouse a digestão nitroperclórica das amostras, em bloco digestor para determinação do teor de Mn no extrato, conforme Malavolta ${ }^{13}$. As duas plantas restantes foram mantidas nos vasos até o final do ciclo para avaliar a produção de grãos. Após o corte, a parte aérea foi separada em folhas + colmos e em panículas. As raízes foram retiradas dos vasos e nas amostras de solo foi analisado o teor de manganês com os extratores Mehlich- $1^{14}$ e DTPA ${ }^{7}$. As análises das plantas de arroz foram semelhantes às realizadas no perfilhamento.

Avaliou-se, também, o efeito residual do manganês aplicado ao solo, com o segundo cultivo de arroz. Nesse, aplicou-se nutrientes com base na análise de solo e adubação de cobertura com $\mathrm{N} \mathrm{e}$ 
K. As avaliações foram semelhantes às efetuadas no primeiro cultivo. Os dados obtidos foram submetidos à análise de variância utilizando-se programa estatístico SISVAR ${ }^{8}$.

Foram efetuadas correlações lineares de Pearson entre os teores de Mn extraído por todos os extratores, com a quantidade de Mn acumulada nas plantas, utilizando o pacote estatístico $\mathrm{SAEG}^{15}$. A recuperação do manganês do fertilizante pela planta foi calculada utilizando-se o Índice de Eficiência Agronômica (IEA) das fontes, em relação ao sulfato de manganês p.a., tal como realizado para fertilizantes contendo zinco $^{4}$, utilizando-se a seguinte expressão:

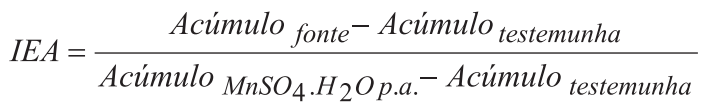

\section{RESULTADOS E DISCUSSÃO}

\section{Difratogramas de raios- $\mathrm{X}$ dos fertilizantes contendo manganês}

Nas Figuras 1 e 2 são mostrados os difratogramas de raios-X (DRX) das amostras de fertilizantes contendo manganês.

$\mathrm{Na}$ análise de DRX de amostras em pó de sulfato de Mn monoidratado PA (F1) foram identificados reflexos variados de 4,$92 ; 4,86 ; 3,83 ; 3,51 ; 3,44 ; 3,36 ; 3,14 ; 2,59 ; 2,58 ; 2,36 ; 2,24$ e $2,14 \AA$, correspondendo aos planos $0 \overline{11} ; 111 ; 020 ; 200$ e $1 \overline{11} ; 211$; $1 \overline{20} ; 2 \overline{2} ; 122 ; 220 ; 0 \overline{31} ; 113 ; 131$, respectivamente, permitindo a identificação do mineral szmikita, $\mathrm{MnSO}_{4} \cdot \mathrm{H}_{2} \mathrm{O}$ (Figura 1).

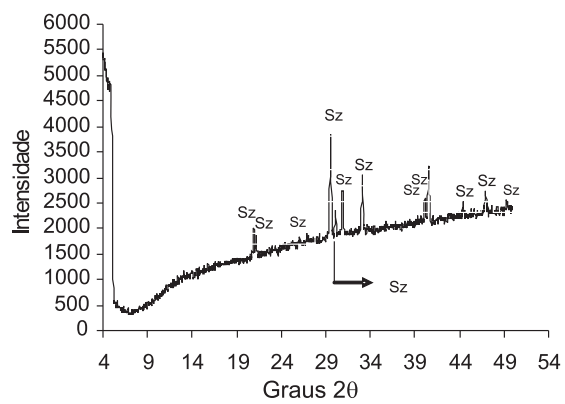

Figura 1. Difratograma de raios- $X$ do fertilizante sulfato de manganês monoidratado PA. Sz: szmikita.

$\mathrm{Na}$ amostra de $\mathrm{MnO}_{2} \mathrm{PA}$ (F4) não se detectou a presença da pirolusita no DRX, inferindo-se que este não se encontra em forma cristalina, e, sim, em formas amorfas, as quais não são identificadas no difratograma de raios-X. Infere-se, pois, que o Mn vindo dessa fonte poderá ser de mais fácil dissolução e, portanto, deverá estar mais disponível às plantas quando adicionado ao solo. Mesmo comportamento foi verificado na amostra de $\mathrm{MnO}_{2}$ Ind. (F5).

$\mathrm{Na}$ amostra de $\mathrm{MnO}$ Ind. (F6), o mineral manganosita, MnO, foi identificado na análise qualitativa de DRX por reflexos de 2,56 e 2,21 A, correspondendo aos planos 111 e 200, respectivamente (Figura 2). Os resultados encontrados pelos DRX com amostras de monóxido e bióxidos de Mn utilizados indicam que a valência (o estado de oxidação) do composto teria menor importância que a cristalinidade com relação à solubilidade do composto. Porém, esses resultados não permitem inferir a despeito da disponibilidade de Mn às plantas vindo dessas fontes.

Para a mistura contendo o $\mathrm{MnO}_{2} \mathrm{PA}+\mathrm{MnO}$ Ind. (F2) observou-se o mesmo comportamento das duas amostras isoladas citadas anteriormente: presença de manganosita com reflexos de 2,56 e 2,21 ̊ e não detecção de formas cristalinas de bióxido de Mn. Comportamento semelhante foi observado para a amostra contendo $\mathrm{MnO}_{2}$ Ind. $+\mathrm{MnO}$ Ind. (F3).

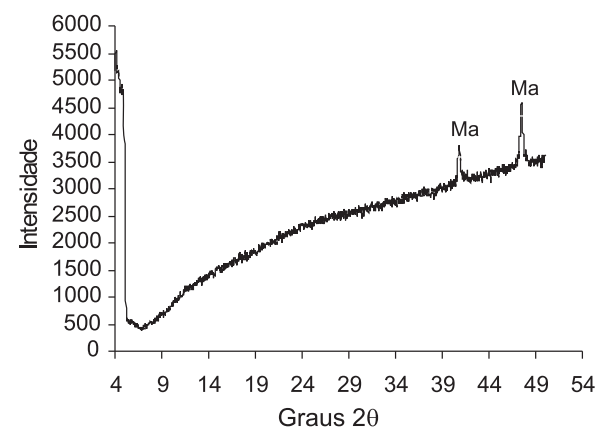

Figura 2. Difratograma de raios-X do fertilizante Monóxido de Mn Ind. Ma: manganosita

\section{Avaliação da solubilidade de manganês contido nos materiais} fertilizantes

Verificou-se variação significativa no teor de Mn das fontes em relação aos diferentes extratores. As solubilidades de $\mathrm{Mn}$ em

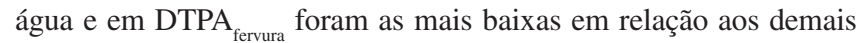
extratores, exceto para o sulfato de $\mathrm{Mn}(\mathrm{F} 1)$, no qual o extrator CNA $_{\text {agitação }}$ apresentou a menor capacidade de solubilização do micronutriente. Nota-se que os teores totais (TT) obtidos, tanto pelo $\mathrm{TT}_{\mathrm{HCl}}$ como pelo $\mathrm{TT}_{\text {água-régia }}$ foram, na maioria das vezes, bem próximos entre si, apesar de estatisticamente diferentes em alguns casos e ambos superiores aos demais extratores. Os teores garantidos apresentaram-se superiores aos teores totais encontrados, exceto para $\mathrm{MnO}_{2}$ Ind. (F5), apesar das diferenças serem bem sutis. De maneira geral, o AC mostrou boa solubilização de Mn das fontes testadas, sendo a extração do Mn no sulfato semelhante à extração total (Tabela 1).

A solução de ácido cítrico $20 \mathrm{~g} \mathrm{~L}^{-1}$ apresenta $\mathrm{pH}$ 2,3. Em pH 2,0, o ácido cítrico apresenta-se predominantemente na espécie $\mathrm{H}_{3}$ Citr e, em menor proporção, na espécie $\mathrm{H}_{2} \mathrm{Citr}$, sendo que a $\mathrm{H}_{2} \mathrm{Citr}^{-}$forma

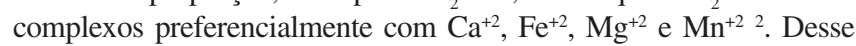
modo, a ação solubilizante da solução do ácido cítrico a $20 \mathrm{~g} \mathrm{~L}^{-1}$ deve estar baseada na associação de dois fatores: ação complexante do ácido cítrico e seus íons e acidez da solução. Parece que o efeito da acidez é mais significativo na química do manganês iônico. $\mathrm{O}$ potencial positivo da reação $\mathrm{Mn}^{0} \rightarrow \mathrm{Mn}^{+2}+2 \mathrm{e}^{-}(\mathrm{E}=1,18$ volts $)$ mostra que o manganês metálico $\left(\mathrm{Mn}^{0}\right)$ dissolve-se (oxida-se) facilmente a $\mathrm{Mn}^{+2}$ em soluções aquosas diluídas. Essa oxidação prossegue naturalmente com o manganês metálico pelo fato de não existir, na superfície do mesmo, uma camada protetora de óxidos, ao contrário dos outros metais anteriores a ele na primeira série de transição ${ }^{16}$. Portanto, o pH 2,3 da solução extratora é um facilitador da maior atividade química do $\mathrm{Mn}^{+2}$ em solução. Porém, a estrutura cristalina e o tamanho da partícula também influem na solubilização ${ }^{17}$. É pertinente comentar que as amostras se encontravam na forma de pó fino (2 $\mathrm{mm}$ - ABNT 10). Esse fato, aliado aos fatores citados anteriormente, pode ter contribuído para maior solubilização das fontes por meio desse extrator.

Observa-se que o Mn contido nos produtos fertilizantes foi sensível às variações do $\mathrm{pH}$ das soluções extratoras. O quelato DTPAMn é muito estável ${ }^{18} \mathrm{em} \mathrm{pH}$ 7,0. Por outro lado, as soluções com caráter mais ácido (tal como o AC-pH- 2,3 e o $\mathrm{H}_{2} \mathrm{SO}_{4} 10 \%$ v/v) têm capacidade de abaixar o $\mathrm{pH}$ e solubilizar o $\mathrm{Mn}$, o que não ocorre com o DTPA de reação alcalina ${ }^{19}$. Desse modo, a acidez das soluções extratoras prevaleceu na solubilização do Mn sobre a capacidade de quelação do DTPA.

Na Tabela 2 encontram-se as solubilidades do Mn nas diferentes fontes, em relação ao teor total encontrado. A água foi pouco 
Tabela 1. Teor de Mn fornecido pelo fabricante (rótulo) e determinado por diversos extratores nos produtos. F1 (sulfato de Mn monoidratado p.a.); F2 (bióxido de Mn p.a. + monóxido de Mn Ind.); F3 (bióxido de Mn Ind. + monóxido de Mn Ind.); F4 (bióxido de Mn p.a.); F5 (bióxido de Mn Ind.); F6 (monóxido de Mn Ind.). Dados médios de três repetições ${ }^{(1)}$

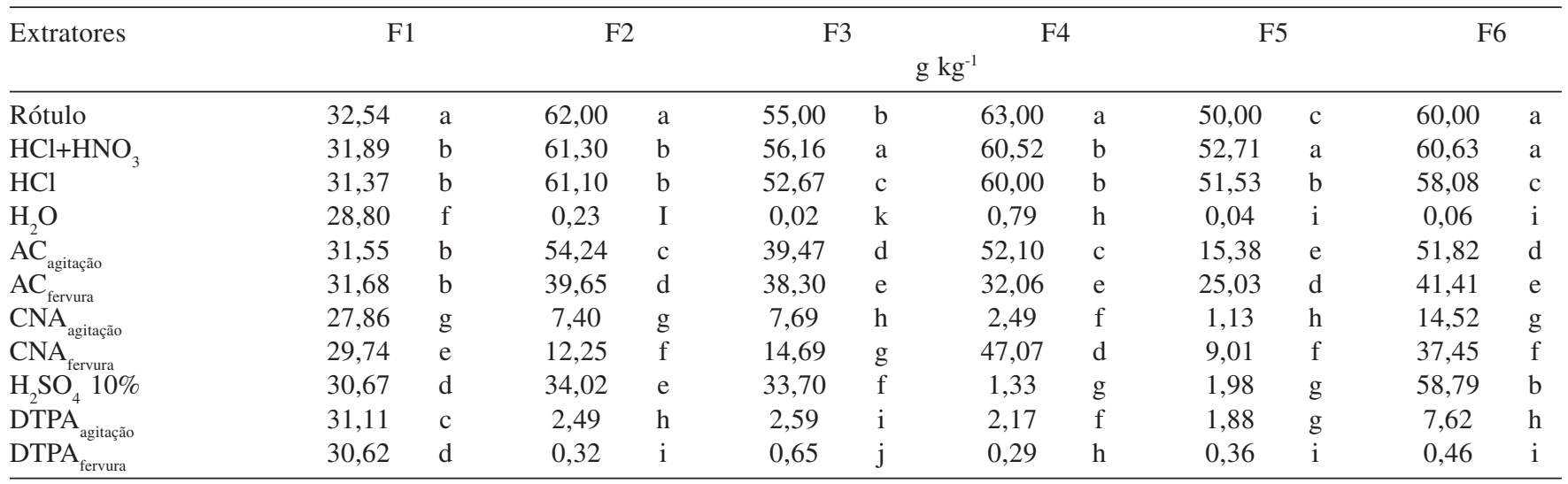

(1) Médias seguidas das mesmas letras, nas colunas, não diferem entre si (Scott e Knott, 5\%).

eficiente para extrair Mn das fontes testadas, excluindo-se o sulfato de Mn- F1 (91,8\%), pois extraiu, em média, cerca de $0,40 \%$ do Mn em relação ao total em $\mathrm{HCl}$. A solubilidade em água é fator determinante da eficiência agronômica no curto prazo, para aplicações localizadas em sulco e produtos na forma granulada ${ }^{1}$. Em pesquisa realizada com fontes de $\mathrm{Mn}$, o manganês do $\mathrm{MnSO}_{4}$ foi mais disponível para plantas de tomate crescidas em solos da Flórida por causa da sua maior solubilidade em água em relação a $\mathrm{MnO}$ e $\mathrm{MnO}_{2}{ }^{20}$. $\mathrm{O} \mathrm{AC}_{\text {agitação }}$ e $\mathrm{o} \mathrm{AC}_{\text {fervura }}$ extraíram bem mais $\mathrm{Mn}$, solubilizando, em média, 75 e $62 \%$, respectivamente, do teor de Mn (valor excluindo o sulfato). Essa tendência de extração foi semelhante à encontrada em trabalho realizado em amostras de fertilizantes com micronutrientes, entre eles o $\mathrm{Mn}^{2}$, e também em formulações de fertilizantes contendo micronutrientes ${ }^{21}$.

Observa-se que, apesar dos extratores testados apresentarem diferença significativa quando a fonte utilizada foi o sulfato de $\mathrm{Mn}$, as mesmas não foram tão intensas como se verifica quando da utilização das fontes não solúveis (Tabela 2). Inclusive, o DTPA, nas duas formas de extração, para a fonte sulfato, resultou em elevada solubilização, cerca de $98,4 \%$ em média, sendo a mesma

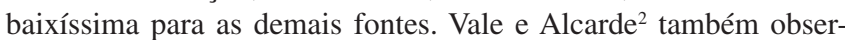
varam que o DTPA (para fontes contendo Mn solúvel) foi o extrator que mais solubilizou Mn.

Para a fonte contendo o $\mathrm{MnO}_{2}$ Ind (F5), o AC, nas duas formas de extração, foi menos efetivo na solubilização desse elemento em relação à extração total (agitação, 29,8\% e fervura, 48,6\%). Comporta- mento semelhante para essa fonte foi observado para CNA, porém, em proporções bem menores (agitação, 2,2\% e fervura, 17,5\%).

$\mathrm{O} \mathrm{H}_{2} \mathrm{SO}_{4} 10 \%$ (v/v), em relação ao total, extraiu de forma considerável o Mn das fontes que continham o MnO, mesmo nas misturas e solubilizou pouco o $\mathrm{Mn}$ das fontes que continham somente o $\mathrm{MnO}_{2}$ (p.a.- 2,2\% e Ind.- 3,8\%), F4 e F5 respectivamente. O

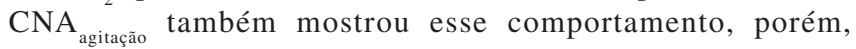
solubilizanando menores quantidades de $\mathrm{Mn}$.

O DTPA, nas duas formas de extração, solubilizou muito pouco o $\mathrm{Mn}$, tanto de formas contendo $\mathrm{MnO}_{2}$ como $\mathrm{MnO}$, exceto para o sulfato, o qual solubilizou cerca de $98,4 \%$ em relação ao total. O $\mathrm{MnO}_{2}$ já se encontra na forma tetravalente, ou seja, na forma não disponível ${ }^{22}$. Desse modo, na presente pesquisa, os bióxidos utilizados na condução do experimento apresentariam uma menor disponibilidade às plantas. Porém, é pertinente comentar que, pelos difratogramas de raios-X das amostras, não foi detectada no $\mathrm{MnO}_{2}$ p.a. (F4) e no $\mathrm{MnO}_{2}$ Ind. (F5) a presença de formas cristalinas, tais como pirolusita, ransdelita, manganita, hausmanita, entre outras, as quais caracterizariam menor disponibilidade imediata às plantas. Este fato revela que, se existe o bióxido na amostra, este não se encontra na forma cristalina. Já nas amostras contendo o MnO Ind., detectou-se a manganosita, inferindo-se que, nesse caso, as fontes contendo o monóxido seriam, a princípio, menos disponíveis às plantas que o bióxido, devido à cristalinidade do produto. A reduzida cristalinidade detectada pelos difratogramas de raios- $\mathrm{X}$ e a elevada superfície de contato das fontes de Mn pulverizadas, com-

Tabela 2. Teores de Mn extraído por diversos extratores em relação ao total extraído em $\mathrm{HCl}$ nos produtos: F1 (sulfato de Mn monoidratado p.a.); F2 (bióxido de Mn p.a. + monóxido de Mn Ind.); F3 (bióxido de Mn Ind. + monóxido de Mn Ind.); F4 (bióxido de Mn p.a.); F5 (bióxido de Mn Ind.); F6 (monóxido de Mn Ind.). Dados médios de três repetições ${ }^{(1)}$

\begin{tabular}{|c|c|c|c|c|c|c|c|c|c|c|c|c|}
\hline \multirow[t]{2}{*}{ Extratores } & \multirow{2}{*}{\multicolumn{2}{|c|}{$\mathrm{F} 1$}} & \multirow{2}{*}{\multicolumn{2}{|c|}{$\mathrm{F} 2$}} & \multirow{2}{*}{\multicolumn{4}{|c|}{$\begin{array}{cc}\mathrm{F} 3 & \mathrm{~F} 4 \\
\% \text { em relação ao teor total em } \mathrm{HCl}\end{array}$}} & \multirow{2}{*}{\multicolumn{2}{|c|}{ F5 }} & \multirow{2}{*}{\multicolumn{2}{|c|}{ F6 }} \\
\hline & & & & & & & & & & & & \\
\hline $\mathrm{H}_{2} \mathrm{O}$ & 91,8 & $\mathrm{a}$ & 0,38 & $\mathrm{~b}$ & 0,04 & $\mathrm{~b}$ & 1,31 & $\mathrm{~b}$ & 0,07 & $\mathrm{~b}$ & 0,10 & $\mathrm{~b}$ \\
\hline $\mathrm{AC}^{2}$ & 100,5 & $\mathrm{a}$ & 88,8 & $\mathrm{~b}$ & 75,2 & $\mathrm{~d}$ & 86,8 & $\mathrm{c}$ & 29,8 & $\mathrm{e}$ & 89,2 & $\mathrm{~b}$ \\
\hline $\mathrm{AC}_{\text {fervura }}$ & 101,0 & $\mathrm{a}$ & 64,9 & $\mathrm{c}$ & 72,9 & $\mathrm{~b}$ & 53,4 & d & 48,6 & $\mathrm{e}$ & 71,3 & $\mathrm{~b}$ \\
\hline $\mathrm{CNA}_{\text {agitacão }}$ & 88,8 & $\mathrm{a}$ & 12,1 & $\mathrm{~d}$ & 14,6 & $\mathrm{c}$ & 4,1 & $\mathrm{e}$ & 2,2 & $\mathrm{f}$ & 25,0 & $\mathrm{~b}$ \\
\hline $\mathrm{CNA}_{\text {fervura }}^{\text {agıtąao }}$ & 94,8 & $\mathrm{a}$ & 20,0 & $\mathrm{e}$ & 27,9 & $\mathrm{~d}$ & 78,4 & $\mathrm{~b}$ & 17,5 & $\mathrm{f}$ & 64,5 & $\mathrm{c}$ \\
\hline $\mathrm{H}_{2} \mathrm{SO}_{4} 10 \%$ & 97,8 & $\mathrm{~b}$ & 55,7 & d & 64,2 & $\mathrm{c}$ & 2,2 & $\mathrm{f}$ & 3,8 & $\mathrm{e}$ & 101,2 & $\mathrm{a}$ \\
\hline DTPA $_{\text {agitacão }}^{4}$ & 97,6 & $\mathrm{a}$ & 0,53 & $\mathrm{~b}$ & 1,23 & $\mathrm{~b}$ & 0,49 & $\mathrm{~b}$ & 0,69 & $\mathrm{~b}$ & 0,80 & $\mathrm{~b}$ \\
\hline DTPA $_{\text {fervura }}$ & 99,2 & $\mathrm{a}$ & 4,07 & $\mathrm{c}$ & 4,93 & $\mathrm{c}$ & 3,62 & $\mathrm{c}$ & 3,64 & $\mathrm{c}$ & 13,1 & $\mathrm{~b}$ \\
\hline
\end{tabular}

(1) Médias seguidas das mesmas letras, nas linhas, não diferem entre si (Scott \& Knott, 5\%). 
binadas com a química do elemento em solução ácida, parecem explicar essas discrepâncias.

A reação $\mathrm{MnO}_{2}+4 \mathrm{H}^{+}+2 \mathrm{e}^{-} \rightarrow \mathrm{Mn}^{+2}+2 \mathrm{H}_{2} \mathrm{O}$ ( $\mathrm{E}=1,23$ volts $)$, com potencial positivo, mostra, ao contrário do que parece, que, em meio ácido, é fácil converter o $\mathrm{MnO}_{2} \mathrm{a} \mathrm{Mn}^{+2}$, espécie bastante ativa em solução aquosa. Além do que, o $\mathrm{MnO}_{2}$, por decomposição térmica, pode produzir uma mistura de $\mathrm{MnO}$ e $\mathrm{Mn}_{2} \mathrm{O}_{3}{ }^{16}$. Porém, são imprescindíveis experimentos com solos e plantas para conclusões dessa natureza.

A correlação entre o teor de Mn garantido pelos fabricantes e o teor total extraído é apresentada na Tabela 3. O coeficiente de correlação encontrado foi de 0,99 para $\mathrm{TT}_{\mathrm{HCl}}$ e 0,98 para $\mathrm{TT}_{\text {ásuarégia }}$, com significância de $1 \%$ e coeficientes angulares da reta próximos de 1 , evidenciando, desse modo, que o teor garantido está presente nos fertilizantes. Em pesquisa realizada com matérias-primas contendo esse elemento foram encontrados valores próximos aos obtidos nesse trabalho (r- $0,87 * *$ e coeficiente angular da reta de 0,90$)^{6}$. Já em trabalho realizado com formulações de fertilizantes contendo Mn foram encontrados valores para o teor total de cerca de duas vezes superiores ao teor garantido ${ }^{21}$. Na Tabela 3 encontram-se também as comparações entre o $\mathrm{TT}_{\mathrm{HCl}}$ nos fertilizantes e os teores solúveis extraídos pelos diferentes extratores. Diante dos resultados obtidos, percebe-se que todos os extratores solubilizaram menos Mn em relação ao TT presente. $\mathrm{O} \mathrm{AC}_{\text {agitacõo }}$ foi o extrator que tendeu a extrair mais, seguido do $\mathrm{AC}_{\text {fervura }}$ O $\mathrm{O}_{2} \mathrm{SO}_{4} 10 \%$, o CNA agitação, o DTPA $\mathrm{Dervura}_{\text {, }}$ a água e o DTPA agitação tiveram, inclusive, correlação negativa com a extração total, evidenciando baixa extração pelos mesmos, conforme observado pelos seus coeficientes angulares (Tabela 3).

Tabela 3. Valores dos coeficientes angulares da reta e dos coeficientes de correlação obtidos entre os teores de manganês garantidos e os teores totais de manganês, e entre os teores totais extraídos pelo $\mathrm{HCl}$ concentrado e os teores solúveis nos diferentes extratores, nas amostras de fertilizantes contendo manganês

\begin{tabular}{|c|c|c|c|c|}
\hline \multirow[t]{2}{*}{ Extrator } & \multicolumn{2}{|c|}{ Garantia $\mathrm{x}$ teor total } & \multicolumn{2}{|c|}{ Manganês total ${ }_{\mathrm{HCl}} \times$ solúvel } \\
\hline & $\begin{array}{l}\text { Coeficiente } \\
\text { angular } \\
\text { da reta }\end{array}$ & $\begin{array}{l}\text { Coeficiente } \\
\text { de correlação } \\
\text { (r) }\end{array}$ & $\begin{array}{c}\text { Coeficiente } \\
\text { angular } \\
\text { da reta }\end{array}$ & $\begin{array}{l}\text { Coeficiente } \\
\text { de correlação } \\
\text { (r) }\end{array}$ \\
\hline $\mathrm{TT}_{\text {áqua régia }}$ & 0,9702 & $0,98 * *$ & - & - \\
\hline $\mathrm{TT}_{\mathrm{HCl}}^{\text {agua regla }}$ & 0,9528 & $0,99 * *$ & - & - \\
\hline Água & - & - & $-0,9815$ & $-0,93 * *$ \\
\hline $\mathrm{AC}_{\text {agitacão }}$ & - & - & 0,7913 & $0,57 * *$ \\
\hline $\mathrm{AC}_{\text {fervura }}$ & - & - & 0,2185 & $0,39^{\mathrm{ns}}$ \\
\hline $\mathrm{CNA}_{\text {agitacão }}^{\text {revura }}$ & - & - & $-0,6922$ & $-0,77 * *$ \\
\hline $\mathrm{CNA}_{\text {fervura }}$ & - & - & 0,0669 & $0,05^{\mathrm{ns}}$ \\
\hline $\mathrm{H}_{2} \mathrm{SO}_{4} 10 \%$ & & & $-0,0135$ & $-0,01^{\mathrm{ns}}$ \\
\hline DTPA $_{\text {agitaço }}^{2}$ & - & - & $-1,0457$ & $-0,94 * *$ \\
\hline DTPA $_{\text {fervura }}$ & - & - & $-0,9437$ & $-0,90 * *$ \\
\hline
\end{tabular}

**, ns- significativo a $1 \%$ e não significativo, respectivamente.

Alcarde e Vale ${ }^{21}$ também encontraram solubilização estatisticamente significativa para o $\mathrm{AC}$ e superior àquela encontrada neste trabalho. Porém, vale ressaltar que trabalharam com formulações fertilizantes, as quais contêm pequenas quantidades das matériasprimas no mesmo volume de solução extratora, o que pode, conforme os autores, aumentar a solubilidade.

\section{Avaliação da disponibilidade de manganês contido nos fertilizantes a plantas de arroz}

Os coeficientes de correlação linear (r) obtidos entre os teores de Mn nos fertilizantes, extraídos pelos diversos extratores, e o acúmulo de Mn nas diferentes partes da plantas de arroz são mostrados nas Tabelas 4 e 5 para o $1^{\circ}$ cultivo e nas Tabelas 6 e 7 para o $2^{\circ}$ cultivo.

Observa-se, pelos resultados da Tabela 4, que o teor total em $\mathrm{HCl}$ não apresentou correlação significativa com o acumulado na matéria seca das diferentes partes das plantas de arroz, indicando que esse extrator se mostrou inadequado para caracterizar a disponibilidade de Mn às plantas. Correlações significativas entre a quantidade acumulada na matéria seca de parte aérea no perfilhamento $\left(1^{\circ}\right.$ cultivo) e os teores de Mn nos fertilizantes foram obtidas quando se utilizaram os extratores $\mathrm{CNA}_{\text {agitaç̃õ }}, \mathrm{DTPA}_{\text {fervura }}$, água, DTPA agitação' , mostrando que $98,81,71$ e $64 \%$, respectivamente, são explicadas pela regressão linear acúmulo na matéria seca por ocasião do perfilhamento/Mn extraído pelos fertilizantes e que esses extratores solubilizaram coerentemente as mesmas formas químicas presentes. Comportamento semelhante foi observado em trabalho realizado com fontes contendo esse micronutriente ${ }^{2}$. Deve-se ressaltar que esses autores também utilizaram plantas de arroz, porém, utilizando o teste de Neubauer e Schneider ${ }^{23}$ (teste de rápida realização- 20 a 22 dias de cultivo em placas de petri contendo areia lavada).

Utilizando-se o acúmulo de Mn na panícula houve também cor-

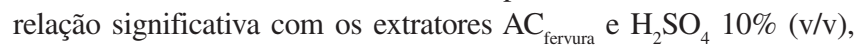
porém, com coeficientes de determinação (59 e $52 \%$, respectivamente) inferiores aos anteriormente citados e com essa mesma ten-

Tabela 4. Coeficientes de correlação linear de Pearson (r) obtidos entre os teores de Mn nos fertilizantes por diferentes métodos de extração e o acúmulo de Mn nas diferentes partes de plantas de arroz $\left(1^{\circ}\right.$ cultivo). PA- parte aérea

\begin{tabular}{lccccc}
\hline Extrator & \multicolumn{5}{c}{ Acúmulo $\left(\mu \mathrm{g}\right.$ vaso $\left.^{-1}\right)$} \\
& $\mathrm{PA}_{\text {perfilhamento }}$ & $\mathrm{PA}_{\text {colheita }}$ & Panícula & Raiz & Total \\
\hline $\mathrm{TT}_{\mathrm{HCl}}$ & $-0,72^{\mathrm{ns}}$ & $0,11^{\mathrm{ns}}$ & $0,26^{\mathrm{ns}}$ & $0,21^{\mathrm{ns}}$ & $-0,12^{\mathrm{ns}}$ \\
Água & $0,84^{*}$ & $-0,01^{\mathrm{ns}}$ & $-0,18^{\mathrm{ns}}$ & $-0,11^{\mathrm{ns}}$ & $0,24^{\mathrm{ns}}$ \\
$\mathrm{AC}_{\text {agitação }}$ & $0,09^{\mathrm{ns}}$ & $0,45^{\mathrm{ns}}$ & $0,49^{\mathrm{ns}}$ & $0,49^{\mathrm{ns}}$ & $0,43^{\mathrm{ns}}$ \\
$\mathrm{AC}_{\text {fervura }}$ & $0,29^{\mathrm{ns}}$ & $0,63^{\mathrm{ns}}$ & $0,77^{*}$ & $0,70^{\mathrm{ns}}$ & $0,70^{*}$ \\
$\mathrm{CNA}_{\text {agitação }}$ & $0,99^{* *}$ & $0,33^{\mathrm{ns}}$ & $0,21^{\mathrm{ns}}$ & $0,31^{\mathrm{ns}}$ & $0,61^{\mathrm{ns}}$ \\
$\mathrm{CNA}_{\text {fervura }}$ & $0,20^{\mathrm{ns}}$ & $0,53^{\mathrm{ns}}$ & $0,28^{\mathrm{ns}}$ & $0,50^{\mathrm{ns}}$ & $0,40^{\mathrm{ns}}$ \\
$\mathrm{H}_{2} \mathrm{SO}_{4}$ 10\% & $0,58^{\mathrm{ns}}$ & $0,62^{\mathrm{ns}}$ & $0,72^{*}$ & $0,74^{*}$ & $0,79^{*}$ \\
$\mathrm{DTPA}_{\text {agitação }}$ & $0,80^{*}$ & $0,00^{\mathrm{ns}}$ & $-0,17^{\mathrm{ns}}$ & $-0,10^{\mathrm{ns}}$ & $0,26^{\mathrm{ns}}$ \\
$\mathrm{DTPA}_{\text {fervura }}$ & $0,90^{* *}$ & $0,11^{\mathrm{ns}}$ & $-0,06^{\mathrm{ns}}$ & $0,05^{\mathrm{ns}}$ & $0,37^{\mathrm{ns}}$ \\
\hline
\end{tabular}

**; *; ns significativo a 1\%, 5\% e não significativo, respectivamente.

Tabela 5. Coeficientes de correlação linear de Pearson (r) obtidos entre os teores de Mn nos fertilizantes por diferentes métodos de extração e o acúmulo de Mn nas diferentes partes de plantas de arroz ( $1^{\circ}$ cultivo) (sem o sulfato de $\mathrm{Mn}$ ). PA- parte aérea

\begin{tabular}{lccccc}
\hline \multirow{2}{*}{ Extrator } & \multicolumn{5}{c}{ Acúmulo $\left(\mu \mathrm{g}\right.$ vaso $\left.^{-1}\right)$} \\
& $\mathrm{PA}_{\text {perfilhamento }}$ & $\mathrm{PA}_{\text {colheita }}$ & Panícula & Raiz & Total \\
\hline $\mathrm{TT}_{\mathrm{HCl}}$ & $0,62^{\mathrm{ns}}$ & $0,34^{\mathrm{ns}}$ & $0,32^{\mathrm{ns}}$ & $0,39^{\mathrm{ns}}$ & $0,41^{\mathrm{ns}}$ \\
Água & $-0,33^{\mathrm{ns}}$ & $-0,07^{\mathrm{ns}}$ & $-0,25^{\mathrm{ns}}$ & $-0,17^{\mathrm{ns}}$ & $-0,21^{\mathrm{ns}}$ \\
$\mathrm{AC}_{\text {agitação }}$ & $0,68^{\mathrm{ns}}$ & $0,47^{\mathrm{ns}}$ & $0,47^{\mathrm{ns}}$ & $0,49^{\mathrm{ns}}$ & $0,54^{\mathrm{ns}}$ \\
$\mathrm{AC}_{\text {fervura }}$ & $0,97^{* *}$ & $0,65^{\mathrm{ns}}$ & $0,76^{\mathrm{ns}}$ & $0,70^{\mathrm{ns}}$ & $0,81^{*}$ \\
$\mathrm{CNA}_{\text {agitação }}$ & $0,96^{* *}$ & $0,71^{\mathrm{ns}}$ & $0,79^{\mathrm{ns}}$ & $0,84^{*}$ & $0,84^{*}$ \\
$\mathrm{CNA}_{\text {fervura }}$ & $0,15^{\mathrm{ns}}$ & $0,54^{\mathrm{ns}}$ & $0,31^{\mathrm{ns}}$ & $0,52^{\mathrm{ns}}$ & $0,38^{\mathrm{ns}}$ \\
$\mathrm{H}_{2} \mathrm{SO}_{4} 10 \%$ & $0,97^{*}$ & $0,63^{\mathrm{ns}}$ & $0,75^{\mathrm{ns}}$ & $0,76^{\mathrm{ns}}$ & $0,80^{*}$ \\
$\mathrm{DTPA}_{\text {agitação }}$ & $0,43^{\mathrm{ns}}$ & $0,67^{\mathrm{ns}}$ & $0,78^{\mathrm{ns}}$ & $0,59^{\mathrm{ns}}$ & $0,70^{\mathrm{ns}}$ \\
$\mathrm{DTPA}_{\text {fervura }}$ & $0,75^{\mathrm{ns}}$ & $0,67^{\mathrm{ns}}$ & $0,63^{\mathrm{ns}}$ & $0,83^{*}$ & $0,71^{\mathrm{ns}}$ \\
\hline
\end{tabular}

**; *; ns significativo a $1 \%, 5 \%$ e não significativo, respectivamente. 
dência estendendo-se para o acúmulo de Mn na matéria seca total.

Quando a fonte solúvel em água (sulfato de Mn p.a., F1) é excluída dos cálculos (justamente pela sua alta solubilidade em água em relação às outras fontes) observa-se uma correlação altamente significativa do $\mathrm{CNA}_{\text {agitacão }}$ com a quantidade acumulada na parte aérea no perfilhamento. Além desse extrator, nessa mesma ocasião, o $\mathrm{AC}_{\text {fervura }}$ e o $\mathrm{H}_{2} \mathrm{SO}_{4} 10 \%$ (v/v) também apresentaram correlações significativas. Mesmo comportamento foi verificado quando se correlacionou com o acúmulo de Mn total. Vale e $\mathrm{Alcarde}^{2}$ também encontraram correlações significativas com os extratores CNA $(r=0,90)$ e AC $(r=0,93)$. Já no segundo cultivo, observou-se que somente o extrator $\mathrm{H}_{2} \mathrm{SO}_{4} 10 \%(\mathrm{v} / \mathrm{v})$ apresentou correlação significativa com o acumulado na matéria seca da parte aérea, tanto no perfilhamento como na colheita. Mesma tendência foi observada para o acúmulo total de Mn (Tabela 6).

Quando a fonte sulfato de $\mathrm{Mn}$ foi isolada ( $2^{\circ}$ cultivo), os extratores $\mathrm{CNA}_{\text {agitação }}, \mathrm{H}_{2} \mathrm{SO}_{4} 10 \%(\mathrm{v} / \mathrm{v})$ e o $\mathrm{DTPA}_{\text {fervura }}$ explicaram bem a correlação entre o acumulado na matéria seca de parte aérea no perfilhamento e os teores de Mn nos fertilizantes (96, 90 e $86 \%$, respectivamente), porém, o DTPA apresentou significância inferior aos outros citados (Tabela 7). Na colheita, os resultados se repetiram para o CNA agitação e para $\mathrm{o}_{2} \mathrm{SO}_{4} 10 \%$ (v/v). Finalmente,

Tabela 6. Coeficientes de correlação linear de Pearson (r) obtidos entre os teores de Mn nos fertilizantes por diferentes métodos de extração e o acúmulo de Mn nas diferentes partes de plantas de arroz $\left(2^{\circ}\right.$ cultivo). PA- parte aérea

\begin{tabular}{|c|c|c|c|c|c|}
\hline \multirow[t]{2}{*}{ Extrator } & \multicolumn{5}{|c|}{ Acúmulo $\left(\mu \mathrm{g}\right.$ vaso $\left.^{-1}\right)$} \\
\hline & $\mathrm{PA}_{\text {perfilhamento }}$ & $\mathrm{PA}_{\text {colheita }}$ & $\begin{array}{c}\text { Panícula } \\
\text { (grãos) }\end{array}$ & Raiz & Total \\
\hline $\mathrm{TT}_{\mathrm{HCl}}$ & $-0,17^{\mathrm{ns}}$ & $-0,33^{\mathrm{ns}}$ & $0,07^{\mathrm{ns}}$ & $0,05^{\mathrm{ns}}$ & $-0,17$ ns \\
\hline Água & $0,27^{\mathrm{ns}}$ & $0,31^{\mathrm{ns}}$ & $0,09^{\mathrm{ns}}$ & $-0,15^{\mathrm{ns}}$ & 0,23 ns \\
\hline $\mathrm{AC}_{\text {agitacão }}$ & 0,28 ns & $-0,08$ ns & $0,41^{\mathrm{ns}}$ & $-0,20^{\mathrm{ns}}$ & $0,16^{\mathrm{ns}}$ \\
\hline $\mathrm{AC}_{\text {fervura }}^{\text {agitacao }}$ & $0,65^{\mathrm{ns}}$ & $0,46^{\mathrm{ns}}$ & $0,60^{\mathrm{ns}}$ & $0,26^{\mathrm{ns}}$ & $0,60^{\mathrm{ns}}$ \\
\hline $\mathrm{CNA}_{\text {agitacão }}$ & $0,70^{\mathrm{ns}}$ & $0,66^{\mathrm{ns}}$ & $0,43^{\mathrm{ns}}$ & $0,20^{\mathrm{ns}}$ & $0,66^{\mathrm{ns}}$ \\
\hline $\mathrm{CNA}_{\text {fervura }}^{\text {agraçao }}$ & 0,23 ns & $-0,14^{\mathrm{ns}}$ & $-0,04$ ns & $-0,14^{\mathrm{ns}}$ & $0,05^{\text {ns }}$ \\
\hline $\mathrm{H}_{2} \mathrm{SO}_{4}$ ervura $10 \%$ & $0,94 * *$ & $0,84^{*}$ & $0,76^{*}$ & 0,63 ns & $0,94 * *$ \\
\hline DTPA $_{\text {agitacão }}^{2}$ & $0,29^{\mathrm{ns}}$ & $0,33^{\mathrm{ns}}$ & $0,90 \mathrm{~ns}$ & $-0,12^{\mathrm{ns}}$ & 0,25 ns \\
\hline $\mathrm{DTPA}_{\text {fervura }}$ & $0,44^{\mathrm{ns}}$ & $0,45^{\mathrm{ns}}$ & $0,21^{\mathrm{ns}}$ & $0,02^{\mathrm{ns}}$ & $0,41^{\mathrm{ns}}$ \\
\hline
\end{tabular}

**; *; ns- significativo a $1 \%, 5 \%$ e não significativo, respectivamente.

Tabela 7. Coeficientes de correlação linear de Pearson (r) obtidos entre os teores de Mn nos fertilizantes por diferentes métodos de extração e o acúmulo de Mn nas diferentes partes de plantas de arroz ( $2^{\circ}$ cultivo) (sem o sulfato de $\mathrm{Mn}$ ). PA- parte aérea

\begin{tabular}{|c|c|c|c|c|c|}
\hline \multirow[t]{2}{*}{ Extrator } & \multicolumn{5}{|c|}{ Acúmulo $\left(\mu \mathrm{g}\right.$ vaso $\left.^{-1}\right)$} \\
\hline & $\mathrm{PA}_{\text {perfilhamento }}$ & $\mathrm{PA}_{\text {colheita }}$ & $\begin{array}{c}\text { Panícula } \\
\text { (grãos) }\end{array}$ & Raiz & Total \\
\hline $\mathrm{TT}_{\mathrm{HCl}}$ & $0,36^{\mathrm{ns}}$ & $-0,06^{\mathrm{ns}}$ & $0,55^{\mathrm{ns}}$ & $-0,24$ ns & 0,22 ns \\
\hline Água & $-0,50^{\mathrm{ns}}$ & $-0,82 *$ & $-0,35$ ns & $-0,79^{\mathrm{ns}}$ & $-0,65^{\mathrm{ns}}$ \\
\hline $\mathrm{AC}_{\text {agitacẵo }}$ & $0,40^{\mathrm{ns}}$ & $0,02^{\text {ns }}$ & $0,46^{\mathrm{ns}}$ & $-0,25^{\mathrm{ns}}$ & $0,25^{\mathrm{ns}}$ \\
\hline $\mathrm{AC}_{\text {fervura }}$ & $0,77^{\mathrm{ns}}$ & $0,59^{\mathrm{ns}}$ & $0,65^{\mathrm{ns}}$ & $0,24^{\mathrm{ns}}$ & $0,70^{\mathrm{ns}}$ \\
\hline $\mathrm{CNA}_{\text {agitacão }}$ & $0,98 * *$ & $0,83^{*}$ & $0,73^{\mathrm{ns}}$ & $0,65^{\mathrm{ns}}$ & $0,95 * *$ \\
\hline $\mathrm{CNA}_{\text {fervura }}$ & $0,20^{\mathrm{ns}}$ & $-0,21 \mathrm{~ns}$ & $-0,06^{\mathrm{ns}}$ & $-0,13^{\mathrm{ns}}$ & $0,02 \mathrm{~ns}$ \\
\hline $\mathrm{H}_{2} \mathrm{SO}_{4} 10 \%$ & $0,95 * *$ & $0,86^{*}$ & $0,76^{\mathrm{ns}}$ & $0,65^{\mathrm{ns}}$ & $0,94 * *$ \\
\hline DTPA $_{\text {agitação }}$ & $0,51^{\mathrm{ns}}$ & $0,75^{\mathrm{ns}}$ & $-0,12^{\mathrm{ns}}$ & $0,48^{\mathrm{ns}}$ & $0,53 \mathrm{~ns}$ \\
\hline DTPA $_{\text {fervura }}$ & $0,93^{*}$ & $0,72^{\mathrm{ns}}$ & $0,65^{\mathrm{ns}}$ & $0,76^{\mathrm{ns}}$ & $0,89 *$ \\
\hline
\end{tabular}

**; *; ns- significativo a $1 \%, 5 \%$ e não significativo, respectivamente. mesmo comportamento do estádio de perfilhamento foi observado para o acúmulo de Mn total.

Os resultados obtidos mostraram que os extratores mais promissores foram o $\mathrm{CNA}_{\text {agitação }}, \mathrm{H}_{2} \mathrm{SO}_{4} 10 \%$ (v/v) e o $\mathrm{AC}_{\text {fervura }}$. Com base nos dados obtidos no $1^{\circ}$ cultivo na época do perfilhamento (época que reflete com maior precisão o estado nutricional de plantas de arroz) observa-se que o $\mathrm{CNA}_{\text {agitação }}$ se repete quando se tem ou não a fonte solúvel em água (sulfato de Mn p.a., F1) e com alta significância. Não se deve descartar também o $\mathrm{H}_{2} \mathrm{SO}_{4} 10 \%$ (v/v) que se correlacionou bem com o $\mathrm{Mn}$ acumulado nas plantas de arroz, porém, vale ressaltar que, mesmo não sendo considerado como teor total, a extração é feita por ácido forte sob aquecimento, sendo praticamente considerado como tal. Esses dois extratores reagiram menos com a fração bióxido, tendo boa extração com a fração monóxido de $\mathrm{Mn}$.

Os extratores AC $2 \%(\mathrm{~m} / \mathrm{v})$, CNA e DTPA mostraram-se promissores para a caracterização da disponibilidade de Mn em fertilizantes contendo esse elemento, com coeficientes de correlação muito próximos entre $\mathrm{si}^{2}$. Porém, na pesquisa realizada por esses autore ${ }^{23}$, um teste de rápida realização (teste de Neubauer e Schneider) em placas de petri foi utilizado, tendo os mesmos comentado que os resultados obtidos não foram definitivos, necessitando de estudos mais aprofundados. Mas definiram que o teor total, conforme exigido pela legislação, não indica a real disponibilidade de micronutrientes nos fertilizantes, o que também ficou caracterizado no presente trabalho.

Com base nos dados de acúmulo nas partes das plantas de arroz para se comparar a solubilização pelos extratores, pode-se calcular o índice de eficiência agronômica (IEA) das diferentes fontes contendo manganês, considerando-se o sulfato de manganês p.a. como padrão (Tabela 8). Observa-se, de maneira geral, que as fontes utilizadas apresentaram IEA principalmente na parte aérea por ocasião do perfilhamento, na dose de $5 \mathrm{mg} \mathrm{dm}^{-3}$, durante o $1^{\circ}$ cultivo, acima de $100 \%$, demonstrando o potencial desses fertilizantes nessa cultura. Em parte, tal fato se deve à utilização das fontes na forma de pó fino ( $2 \mathrm{~mm}$ - ABNT 10) aumentando sua eficiência e parcial imobilização do sulfato nesse estádio. Menores IEA foram encontrados para as fontes contendo o $\mathrm{MnO}_{2}$ p.a. (F4) e Ind (F5).

É pertinente comentar que a solubilização dos fertilizantes, utilizando-se o $\mathrm{CNA}_{\text {agitação }}$ e $\mathrm{o}_{2} \mathrm{SO}_{4} 10 \%$ (v/v) (Tabela 2), foi semelhante ao que ocorreu durante o cultivo das culturas, com a solubilidade das fontes em relação ao teor total superior para $\mathrm{o}_{2} \mathrm{SO}_{4}$ $10 \%$ (v/v) em relação ao CNA agitação No caso do sulfato de Mn (F1), foi solubilizado praticamente todo o Mn. As fontes contendo as misturas (F2 e F3) e o MnO Ind. (F6) disponibilizaram mais Mn que as fontes contendo o $\mathrm{MnO}_{2}$ p.a. (F4) e Ind. (F5) de forma isolada. Desse modo, em termos de eficiência agronômica, existem similaridades entre as fontes de Mn solúveis, tanto em CNA como em $\mathrm{H}_{2} \mathrm{SO}_{4} 10 \%$ (v/v), em qualquer dose de $\mathrm{Mn}$.

Pesquisas anteriores apontaram a solução de CNA como promissora na avaliação de zinco ${ }^{4}$ e de cobre ${ }^{24}$ em fertilizantes. Diante disso, para a extração do Mn, sugere-se a adoção de CNA na diluição (1+9), com agitação por $1 \mathrm{~h}$, pelas características do extrator e pela praticidade, uma vez que a solução será a mesma utilizada nas avaliações de cobre e de zinco.

\section{CONCLUSÕES}

Os fertilizantes contendo Mn apresentam solubilidade diferenciada desse micronutriente, conforme o método de extração utilizado. Os teores de Mn disponível foram diferentes daqueles obtidos pela determinação do teor total. 
Tabela 8. Índice de Eficiência Agronômica para as fontes de Mn utilizadas, em relação ao sulfato de Mn monoidratado p.a.. F1 (sulfato de Mn monoidratado p.a.); F2 (bióxido de Mn p.a. + monóxido de Mn Ind.); F3 (bióxido de Mn Ind. + monóxido de Mn Ind.); F4 (bióxido de Mn p.a.); F5 (bióxido de Mn Ind.); F6 (monóxido de Mn Ind.). Dados médios de três repetições. PA- parte aérea

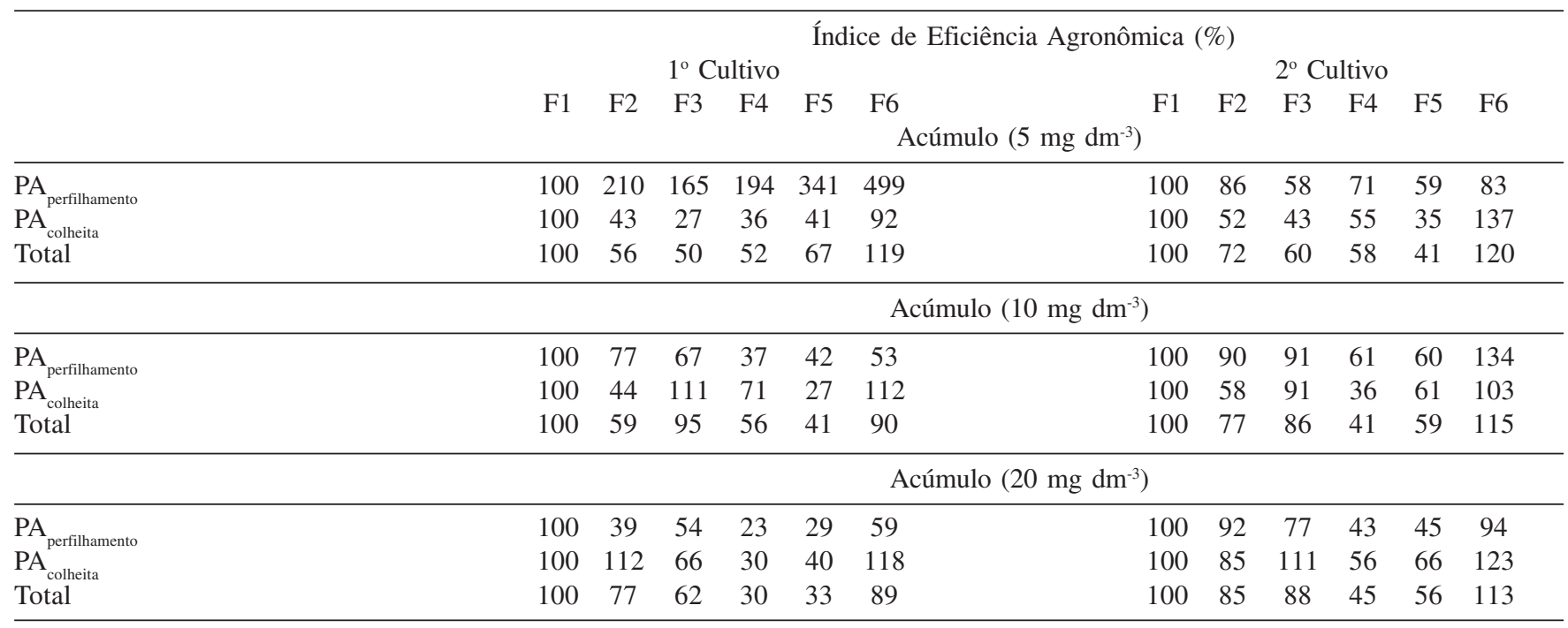

Todas as fontes testadas foram eficientes em prover Mn às plantas. As fontes contendo o bióxido de $\mathrm{Mn}$, tanto p.a. quanto o Ind. disponibilizaram menores quantidades do nutriente às plantas de arroz.

Todas as fontes apresentam efeito residual de Mn no solo, após o segundo cultivo das plantas de arroz (IEA $-2^{\circ}$ cultivo).

O citrato neutro de amônio (1+9), na relação 1:100 e com agitação por $1 \mathrm{~h}$, mostra-se adequado para a determinação do teor de Mn disponível em fertilizantes, uma vez que o método de extração pelo teor total, tal como requerido pela legislação brasileira, não apresentou correlação significativa com o acumulado em plantas de arroz.

\section{REFERÊNCIAS}

1. Lopes, A. S.; Micronutrientes - Filosofias de aplicação e eficiência agronômica, $1^{\text {a }}$ ed., ANDA: São Paulo, 1999.

2. Vale, F.; Alcarde, J. C.; R. Bras. Ci. Solo 1999, 23, 441.

3. Rodella, A. A.; Alcarde, J. C. Em Legislação sobre micronutrientes e metais pesados; Ferreira, M. E.; Cruz, M. C. P. da; Van Raij; B.; Abreu, C. A., eds.; CNPq/FAPESP/POTAFOS: Jaboticabal, 2001, cap. 22.

4. Vale, F.; Alcarde, J. C.; R. Bras. Ci. Solo 2002, 26, 655.

5. Ministério da Agricultura, Brasil; Análises de corretivos, fertilizantes e inoculantes - Métodos oficiais, Lanarv: Brasília, 1983.

6. Vale, F.; Dissertação de Mestrado, Universidade de São Paulo, Brasil, 1997.

7. Lindsay, W. L.; Norvell, W. A.; Soil Sci. Soc. Am. J. 1978, 43, 421.

8. Ferrera, D. F.; Resumos da $45^{a}$ Reunião Anual da Região Brasileira da Sociedade Internacional de Biometria, São Carlos, Brasil, 2000.
9. Scott, A. J.; Knott, M. A.; Biometric 1974, 30, 507.

10. Embrapa; Centro Nacional de Pesquisa de Solos, Sistema brasileiro de classificação de solos, Rio de Janeiro, 1999.

11. Embrapa; Centro Nacional de Pesquisa de solos- Manual de métodos de análise de solos, $2^{\mathrm{a}}$ ed, Rio de Janeiro, 1997.

12. Alvarez, V. V. H.; Ribeiro, A. C. Em Calagem; Ribeiro, A. C.; Guimarães, P. T. G.; Alvarez V. V. H., eds.; Comissão de Fertilidade do Solo do Estado de Minas Gerais: Viçosa, 1999, cap. 8.

13. Malavolta, E.; Elementos de nutrição mineral de plantas, $1^{a}$ ed., Ceres: São Paulo, 1980.

14. Mehlich, A.; Determination of $\mathrm{P}, \mathrm{Ca}, \mathrm{Mg}, \mathrm{K}, \mathrm{Na}$ and $\mathrm{NH}_{4}$, Raleigh: North Carolina Soil Test Division, 1953.

15. Ribeiro Jr., J. I. R.; Análises Estatísticas no Saeg, $1^{\mathrm{a}}$ ed., UFV: Viçosa, 2001.

16. Mahan, B.; Química, um curso universitário, $2^{\mathrm{a}}$ ed., Ed. Edgard Blucher: São Paulo, 1977.

17. Alcarde, J. C.; Ponchio, C. O.; R. Bras. Ci. Solo 1979, 3, 173.

18. Norvell, W. A. Em Reactions of metal chelates in soil and nutrient solutions; Mortvedt, J. J.; Cox, F. R.; Shuman, L. M.; Welch, R. M., eds.; Soil Science Society of America: Madison, 1991, cap. 5.

19. Abreu, C. A.; Van Raij, B.; Bragantia 1996, 55, 357.

20. Fiskel, J. G. A.; Mourkides, G. A.; Plant Soil 1955, 6, 313.

21. Alcarde, J. C.; Vale, F.; R. Bras. Ci. Solo 2003, 27, 363.

22. Mortvedt, J. J. Em Tecnologia e produção de fertilizantes com micronutrientes. Presença de elementos tóxicos; Ferreira, M. E.; Cruz, M. C. P. da; Van Raij; B.; de Abreu, C. A., eds.; CNPq/FAPESP/POTAFOS: Jaboticabal, 2001, cap. 10.

23. Catani, R. A.; Bergamin Filho, H.; Esalq 1961, 18, 287.

24. Bastos, A. R. R.; Tese de Doutorado, Universidade Federal de Lavras, Brasil, 2004. 